\title{
LOS NUEVOS RETOS DEL DERECHO A LA IDENTIDAD EN EL PERÚ: DESDE LA HETEROASIGNACION HACIA LA AUTODETERMINACIÓN
}

\section{THE NEW CHALLENGES OF THE RIGHT TO IDENTITY IN PERU: FROM HETERO ASSIGNMENT TO SELF-DETERMINATION}

\author{
Maria-Pía Guadalupe Díaz Díaz \\ Universidad de Turín \\ Turín- Italia \\ https: / / orcid.org/0000-0002-4645-5591 \\ mariapia.gdiaz@gmail.com
}

\section{Resumen:}

El presente estudio analiza la situación actual del modelo de reconocimiento de la identidad de género vigente en el Perú, un modelo heteroasignado que se viene replicando en los casos concretos ante la justicia ordinaria y que se lee de forma separada de la reciente Opinión Consultiva OC-24/17 de la Corte Interamericana de Derechos Humanos. Se ha logrado un importante desarrollo jurisprudencial en materia constitucional que ha llegado hasta el reconocimiento de un derecho a la identidad de género; sin embargo, es necesario ahondar en la problemática que ahora se centra en la forma y alcances de este reconocimiento, donde la autodeterminación se presenta como un reto pendiente y necesario desde la óptica de los Derechos Humanos.

Palabras clave: Derecho a la identidad, identidad de género, personas trans, LGTBI, autodeterminación.

\begin{abstract}
:
This study analyzes the current situation of the constitutional model for the recognition of gender identity in force in Peru, a hetero-assigned model that has been replicated in specific cases before the ordinary courts and that is read separately from the recent Advisory Opinion OC-24/17 of the Inter-American Court of Human Rights. There has been an important jurisprudential development in constitutional matters that has reached the recognition of a right to gender identity; however, it is necessary to delve into the problem that now focuses on the form and scope of this recognition, where self-

Magíster en Derecho Constitucional por la Universidad de Sevilla (España). Magíster en Estudios Interdisciplinares de Género por la Universidad de Salamanca (España). Ex Becaria Universidad de Salamanca. Doctoranda en Derecho en la Universidad de Turín (Italia). Miembro de la Asociación de Derecho Público Comparado y Europeo (Italia).
\end{abstract}


determination is presented as a pending and necessary challenge from the perspective of Human Rights.

Key words: Right to identity, gender identity, trans people, LGTBI, selfdetermination

\section{INTRODUCCIÓN}

Las personas trans son un grupo minoritario históricamente discriminado que hasta la fecha en diferentes realidades todavía no recibe un justo y oportuno reconocimiento de su identidad de género. Realidades como la peruana donde no existe una legislación específica por la cual tengan reconocida su identidad en un breve plazo, sin mayores trámites, considerando únicamente su autopercepción y sin la exigencia de requisitos abusivos que vulneren sus derechos humanos o perpetúen su patologización (Díaz Díaz 2020). Contrario sensu, esto se traduce en procesos rígidos como es el proceso judicial donde se valora documentación referida a los cambios físicos practicados, así como la existencia de un diagnóstico que pruebe su identidad de género. Los primeros, que no siempre serán deseados en su totalidad y que a la vez traerán severos efectos secundarios en la salud; con los segundos, un tercero en calidad de médico tiene el poder de decidir sobre la identidad de otra persona mientras la somete a un proceso patologizante de prueba de su identidad. Estamos entonces frente a un proceso heteroasignado, de manera que las personas trans deben estar sujetas a su cumplimiento para tener finalmente reconocida su identidad sentida y vivida en los documentos oficiales (Díaz Díaz 2020).

El derecho a la identidad en el Perú ha tenido un importante desarrollo a través de la jurisprudencia del Tribunal Constitucional. Nuestro máximo intérprete de la Constitución adoptó la doctrina de la identidad personal del Profesor Fernández Sessarego y reconoció que está compuesta por elementos objetivos y subjetivos, siendo que a través de la última sentencia del caso Ana Romero Saldarriaga, coloca al sexo como un elemento subjetivo y por ende dinámico y mutable de la identidad. Pero todo no termina ahí, efectivamente tener el reconocimiento constitucional de este derecho es un gran avance; sin embargo, todavía queda un tramo pendiente y es el referido al modelo de reconocimiento y sus alcances.

La problemática peruana actual ha mutado, ya no se centra en la falta de un reconocimiento a la identidad de género, sino en la forma y alcances de este reconocimiento. Estamos ante un fallo constitucional que no ha dejado claro el criterio de reconocimiento a aplicar por los magistrados. No 
se ha elaborado una doctrina clara basada en la autodeterminación, por el contrario, se ha destinado el conocimiento de estos casos a la justicia ordinaria donde se lleve a cabo una actividad probatoria.

Es necesario entender que el reconocimiento de la identidad de género de las personas trans abre la puerta a que estas minorías puedan ejercer sus demás derechos. Que mientras dure un proceso judicial o mientras preparan sus medios probatorios para iniciar ese proceso judicial se ven anulados como personas en una sociedad que rechaza lo diverso y que también son rechazados por el propio Estado. Al no tener reconocida su identidad sentida y vivida de forma oportuna, las discriminaciones sobre este grupo minoritario se acentúan. Ello se traduce en los diversos problemas que atacan a esta población, dentro de los cuales principalmente se encuentra la violencia por la manifestación de su identidad de género, la falta de oportunidades de trabajo o su permanencia en ellos y el difícil acceso a la atención sanitaria. Estamos frente a una problemática muy delicada que requiere una urgente respuesta legislativa que aborde la autodeterminación como principio base.

\section{LA IDENTIDAD Y SU DESARROLLO DOCTRINARIO EN EL PERÚ}

Sobre el derecho a la identidad, como sabemos, ha existido un importante desarrollo constitucional en el Perú, sin embargo, antes de dicho desarrollo, fue la doctrina la que estuvo a cargo de sus primeros y sólidos planteamientos. Tal es así que el principal exponente fue el profesor peruano Carlos Fernández Sessarego, pionero en la teoría de la identidad personal en Latinoamérica y el Perú.

El profesor la definió como "el conjunto de atributos y características tanto estáticas como dinámicas que individualizan a la persona en sociedad. Se trata de todos aquellos rasgos que hacen posible que cada cual sea uno mismo y no otro" (Fernández Sessarego, La Constitución comentada 2006, p. 18). Esta teoría de la identidad personal se sustenta en la libertad que como señala el mismo autor "constituye el ser del hombre, esta permite que cada ser humano realice, de acuerdo con su decisión, su único, singular e irrepetible proyecto de vida...cada ser humano tiene derecho a ser él y no otro" (Fernández Sessarego, 2010, págs. 733-734). Y al hablar de libertad, hablamos del existencialismo, esta corriente filosófica que redescubre al ser humano como ser libre, aquel ser creativo, responsable, itinerante, en continuo movimiento. De esta manera, siendo que a través de la libertad cada persona forja su propio proyecto de vida, es que la persona establece su identidad, su ser, es decir la identidad encuentra su fundamento también en la libertad de la persona humana y forma parte del proyecto de vida. 
Cabe señalar que, como antecedente a esta teoría, tenemos el caso italiano en 1974 cuando una sentencia de la Corte Suprema hizo referencia a ella como un nuevo interés del ser humano digno de ser tutelado jurídicamente. Sin embargo, se debe al jurista Adriano de Cupis su denominación desde 1961, pese a que en este momento la óptica era limitada dado que solo consideraba como identidad a los signos distintivos de la persona que aluden a una visión estática (Zamudio 2010, pp. 94-95). Posteriormente, fue la Corte di Cassazione italiana que en 1985 la reconoce como un derecho jurisprudencial en Italia, y la define como:

Cada sujeto tiene un interés, generalmente considerado como merecedor de tutela jurídica, de ser representado en la vida de relación con su verdadera identidad, tal como ésta es conocida o podría ser conocida en la realidad social, general o particular, con aplicación de los criterios de la normal diligencia y de la buena fe subjetiva (Fernández Sessarego, 2015, págs. 94-95).

El profesor Fernández Sessarego, para elaborar su teoría en $1988^{58}$, toma en cuenta la jurisprudencia italiana en la materia, pero considerando que la identidad biológica también merece ser incluida dentro de la identidad personal. Bajo su postura, la identidad personal debe reunir todo lo que constituye la plena realidad existencial de una persona y por ende debe contemplar tanto la identidad estática como la identidad dinámica. Dicho de este modo, diferencia dos tipos de identidad personal, aquélla estática que se mantiene y que no varía en el tiempo, y, de otro lado, la identidad dinámica, que se fundamenta en la libertad y dignidad humana, en atención a la naturaleza del ser del hombre de ir definiendo los aspectos trascendentales a lo largo de su vida por lo que pueden variar.

Cabe señalar que, la identidad estática también es generalmente confundida con la identificación, término que se vino usando en el Perú para referirse erróneamente a la identidad en general, sin diferenciar sus aspectos. Dado que se entendía que los aspectos de la persona no variaban con el tiempo. Entonces, podemos citar como ejemplos de los elementos objetivos o lo que se conoce como identidad estática a los datos referidos al lugar y fecha de nacimiento, quienes son los progenitores, entre otros que por su naturaleza no varían en el tiempo, al no depender del desarrollo de la persona en atención a su libertad y dignidad. Mientras que los elementos

Esta teoría fue presentada en 1988 en la ponencia titulada El derecho a la identidad personal, posteriormente publicada en la obra colectiva "Tendencias actuales del derecho privado y el sistema jurídico latinoamericano" en 1990 por la Editorial Cultural Cuzco. Obra que recoge las actas del Congreso Internacional desarrollado en Lima del 5 al 7 de setiembre de 1988, organizado por el Ilustre Colegio de Abogados de Lima y la Associazione di Studi Sociali Latinoamericani (ASSLA). 
subjetivos o lo que el profesor denomina la identidad dinámica vendrían a ser la orientación sexual, las ideologías políticas, etc.

Ambos aspectos requieren de protección y regulación legal. Por otro lado, realiza un interesante análisis diferenciando el derecho a la identidad con el derecho a la intimidad, siendo que en el primero está referido al reconocimiento legal de la proyección que tiene un sujeto sobre sí mismo en atención a su identidad para lograr una protección jurídica sobre ellos. Mientras que la segunda es la no representación en la esfera pública de sus aspectos más personales, que generalmente están ligados con aquélla proyección de sí mismo (Fernández Sessarego, 2015, pp. 681-682). Cabe señalar que el estudio del Profesor Fernández Sessarego fue influyente para incluir en la Constitución Peruana de 1993, actualmente vigente, el derecho a la identidad en el artículo 2 sobre los derechos fundamentales.

En ese sentido, podemos resumir el derecho a la identidad personal como aquel derecho de ser nosotros mismos y que esa elección sea reconocida y protegida jurídicamente, con la finalidad de que nuestra identidad refleje lo que somos tanto en el aspecto estático y dinámico. Esto último, de acuerdo a la construcción que realizamos de nosotros mismos, en atención a nuestra libertad y como seres con dignidad.

\section{LA PROTECCIÓN JURÍDICA DEL DERECHO A LA IDENTIDAD DE LAS PERSONAS TRANS: EL MODELO CONSTITUCIONAL ADOPTADO POR EL TRIBUNAL CONSTITUCIONAL PERUANO}

En Perú actualmente no existe una ley específica de protección del derecho a la identidad de las personas trans, pero lo que sí existe es una protección constitucional. En efecto, la Constitución Política del Perú regula que: "Toda persona tiene derecho: 1 . A la vida, a su identidad, a su integridad moral, psíquica y física y a su libre desarrollo y bienestar. El concebido es sujeto de derecho en todo cuanto le favorece" (Const., 1993, art. 2). Respecto a este derecho, el Tribunal Constitucional del Perú ha desplegado un desarrollo jurisprudencial bajo tres sentencias de gran relevancia para el análisis del tema.

Como lo hemos señalado en un estudio anterior (Agurto Gonzales y Díaz Díaz 2020), este desarrollo se dio inicio en 2006 con el caso Karen Mañuca Quiroz Cabanillas, el cual consideramos el antecedente más importante en la materia, dado que, en atención a la correlación entre los derechos fundamentales y la dignidad humana, por primera vez, se otorga un contenido al derecho a la identidad personal como elemento esencial 
para garantizar una vida digna (Expediente 2273-2005-PA/TC, 2006, fj. 7). De esta manera, el derecho fundamental a la identidad personal se sustenta en la dignidad humana, por ende, goza de una doble dimensión o un doble carácter, esto es, un contenido objetivo y subjetivo. El primero impone a los poderes públicos el deber positivo de proteger ese derecho y el deber de abstenerse de realizar algún acto contrario a su deber de protección. El contenido subjetivo, la facultad del titular del derecho de defenderlo frente a terceros ya sea el Estado o los particulares (Villaverde, 2004).

En esta sentencia además se define al sexo del individuo, como aquel compuesto por diversos elementos, incluyendo el psicológico y social (Agurto Gonzales y Díaz Díaz 2020). En línea con ello agrega que “al momento de nacer la persona solo se toma en cuenta el sexo anatómico, ya que la personalidad del recién nacido, que expresará su identidad, recién comenzará a desarrollarse." (Expediente 2273-2005-PA/TC, 2006, fj. 15). Es por ello que define el derecho a la identidad como como,

El derecho que tiene todo individuo a ser reconocido estrictamente por lo que es y por el modo cómo es. Vale decir, el derecho a ser individualizado conforme a determinados rasgos distintivos, esencialmente de carácter objetivo (nombres, seudónimos, registros, herencia genética, características corporales, etc.) y aquellos que se derivan del propio desarrollo y comportamiento personal, más bien de carácter subjetivo (ideología, identidad cultural, valores, reputación, etc.)" (Expediente 2273-2005-PA/TC, 2006, fj. 21).

Con esto se evidencia que el Tribunal Constitucional asume una postura sobre el sexo de las personas que va más allá del aspecto únicamente biológico, considerando también los elementos psicosociales en su composición y que éste se desarrolla a lo largo de la vida en línea con la personalidad de cada uno, aunque no llega a incluirlo en la casificacion como un componente subjetivo o dinámico de la identidad. Cabe señalar que en esta sentencia se admite el cambio de nombre de la demandante, en atención a que lo solicitado se restringió solo a ese extremo (Agurto Gonzales y Díaz Díaz 2020).

Seguidamente, en 2014 con el caso Pamela Estela Mendoza Moreno, el Tribunal Constitucional adopta una posición estrictamente biologicista sobre el sexo de las personas y sostiene que:

Para el Derecho entonces el sexo viene a ser el sexo biológico, el sexo cromosómico o genético instaurado en el momento de la fecundación del óvulo por el espermatozoide, que determina el sexo femenino o 
masculino: cromosomas XX (femenino), cromosomas XY (masculino). La diferencia entre los sexos responde, pues, a una realidad extrajurídica y biológica que debe ser constitucionalmente respetada por fundarse en "la naturaleza de las cosas" (artículo 103 de la Constitución), y en tanto que la ciencia aporta que el sexo cromosómico no se puede cambiar, el sexo es indisponible para el individuo. (Expediente 1392013-PA/TC, 2014, fj. 5).

Como podemos advertir, en esta sentencia se asume la doctrina de la indisponibilidad del sexo de las personas, considerando que este tiene un carácter objetivo dentro de la clasificación realizada en la sentencia anterior, en la cual no se llegó a establecer como un elemento dinámico. Nótese que al definir al sexo solo considera el elemento biológico, dejando de lado el componente psicosocial. Toma provecho entonces de la clasificación abierta dejada en la sentencia anterior y posiciona al sexo en el plano objetivo, debiendo quedar ello establecido en el registro civil como una exigencia constitucional. Esto trajo como consecuencia fatal, la vulneración del derecho de acceso a la justicia de las minorías trans, dado que se estableció que no procedía solicitar este tipo de reconocimiento. Recordemos que la identidad personal como un derecho fundamental basado en la dignidad de las personas, permite su exigencia de protección ante los órganos jurisdiccionales, sin embargo, a través de esta sentencia se cerró esta facultad, negando la posibilidad a las personas trans tener un documento de identidad que refleje su identidad sentida y vivida (Agurto Gonzales y Díaz Díaz 2020).

Finalmente, en 2016 con el caso Ana Romero Saldarriaga, el Tribunal Constitucional deja sin efecto la doctrina del fallo anterior para dar paso a una concepción mejor elaborada del derecho a la identidad en sus ambas vertientes (Agurto Gonzales y Díaz Díaz 2020). Señalando que,

La realidad biológica, a tenor de lo expuesto, no debe ser el único elemento determinante para la asignación del sexo, pues éste, al ser también una construcción, debe comprenderse dentro de las realidades sociales, culturales e interpersonales que la propia persona experimenta durante su existencia se caería en un determinismo biológico que reduciría la naturaleza humana a una mera existencia física y ello obviaría que el ser humano es un ser también psíquico y social (Expediente 6040-2015-PA/TC, 2016, fj. 13).

Partiendo de ello, se reconoce la existencia de un derecho a la identidad de género, como aquel que forma parte del contenido del derecho a la identidad personal (Agurto Gonzales y Díaz Díaz 2020), y que define como: 
... conjunto de vivencias que denotan una expresión propia del ser humano y que le permite distinguir de otras personas. La forma en que ella decide no seguir los patrones convencionales que, dentro de las prácticas sociales, permiten identificar a una persona como "hombre" o "mujer", es, ineludiblemente, un aspecto esencial de la manera en que ha decidido desarrollar su vida, y que, en ese sentido, merece tutela constitucional al formar parte de su identidad (Expediente 60402015-PA/TC, 2016, fj. 14).

De esta manera, vemos cómo el desarrollo de la jurisprudencia del Tribunal Constitucional ha conducido al reconocimiento de un nuevo derecho como consecuencia de una interpretación evolutiva de la Constitución y en amparo del artículo 3 de la misma. Esto con la finalidad de proteger los derechos constitucionales y que también constituyen derechos humanos, como ha sido reconocido por la Corte Interamericana, sobre todo de aquellos grupos minoritarios que no se encontraban en la mirada del debate del constituyente de 1993. Es por ello, la labor interpretativa del máximo intérprete ocupa una función de vital importancia para la protección de los derechos, en atención a que la Constitución es una norma de mínimos (Agurto Gonzales y Díaz Díaz 2020).

No hay dudas que el avance en la materia ha sido neto, sin embargo, vemos también que esta sentencia ha dejado un vacío importante y es que no ha determinado con claridad el modelo a aplicar por parte de la judicatura ordinaria a los casos concretos. Esto es, un modelo basado en la autodeterminación, donde únicamente se requiera del consentimiento libre e informado del solicitante; o un modelo basado en la heteroasignación, donde, por el contrario, se requiere probar la identidad a través de una tercera persona, que generalmente es un profesional de la salud que la determina con un diagnóstico o informe médico.

En ese sentido, una aproximación al modelo constitucional que nos deja esta sentencia se puede extraer cuando deriva el conocimiento de las causas a la justicia ordinaria a través del proceso sumarísimo, así como cuando sostiene que "(...) corresponde dejar a salvo el derecho de la parte recurrente a fin de que, si lo estimara conveniente, lo haga valer en el marco de un proceso que cuente con mayor actividad probatoria" (Expediente 6040-2015-PA/TC, 2016, fj. 28). Cuando se habla de una actividad probatoria dentro de un proceso judicial, en principio estamos hablando de un proceso contencioso donde se debe probar la pretensión y los hechos alegados, probar la identidad de género, que trae como consecuencia una valoración por parte del magistrado de la documentación que demuestre que la persona se identifica con el sexo opuesto al de su nacimiento. 


\section{LA PROBLEMÁTICA JURÍDICA DEL MODELO VIGENTE EN EL PERÚ: LA NECESIDAD DE UN MODELO DE RECONOCIMIENTO BASADO EN LA AUTODETERMINACIÓN DE LA IDENTIDAD DE GÉNERO}

De acuerdo a lo señalado en el punto anterior, estamos hablando, entonces, que en Perú rige a la fecha un modelo heteroasignado de reconocimiento de la identidad de género, donde será necesario siempre que la persona cuente con el aval de una tercera persona para la prueba de la identidad, esto es, un diagnóstico médico. Se trata entonces de un sistema de certificación externa de la identidad de una persona, que generalmente, también importa no solo las características psíquicas sino también físicas, esto es que la persona se haya sometido a ciertas modificaciones corporales, para que sea amparado el cambio de nombre y sexo en los registros.

Tal es así que la práctica judicial, en la Sentencia del Expediente nro. 05684 del Segundo Juzgado Civil de Paucarpata - Arequipa, de fecha 5 de enero de 2018 sobre cambio de sexo, nos confirma esa realidad. En esta sentencia, el magistrado ampara la pretensión sobre cambio de sexo solicitada por A.A.V.G., donde analiza la documentación aportada por el demandante consistente en: certificado psicológico donde se acredita el trastorno de identidad de género, certificado médico por el cual se acredita la intervención quirúrgica de extirpación de mamas, extracción de útero y aparato reproductor femenino total.

Sostiene que, "... se le aprecia al accionante con todos los rasgos físicos exteriores de un varón, acreditándose una vez más que se trata de un caso de transexualismo" (A.A.V.G, 2018, fj. 4). Asimismo, hace referencia a la declaración del demandante en audiencia y dos testimoniales que corroboran ello, para concluir que:

.. al amparo de los derechos fundamentales a la identidad de la persona y de sexo, fundamentalmente dinámica en ambos casos; en concordancia con el derecho fundamental a la libertad, desarrollo y bienestar de la persona, protegiendo el proyecto de vida en este caso de una persona transexual, es que consideramos pertinente atender la pretensión incoada (A.A.V.G, 2018, fj. 4).

Esta es una muestra de cómo se viene reconociendo el derecho a la identidad de las personas trans en el Perú hasta la fecha. Se continúa sometiendo a las personas trans a un proceso judicial para el reconocimiento de su identidad, lo que implica un tiempo de espera considerando la carga procesal, 
la decadencia del sistema judicial peruano y sobre todo un corto conocimiento en materia de diversidad (Agurto Gonzales y Díaz Díaz 2020). Además, tener que reunir una serie de requisitos para probar la identidad, como lo hemos visto en el caso citado y lo que es valorado por el magistrado para reconocer el derecho. Estamos hablando entonces ¿de un verdadero derecho a la identidad? mientras se sigue valorando que un tercero realice su comprobación.

Estos medios probatorios sobre la identidad de género suponen un sacrificio, donde entran en juego derechos fundamentales a la integridad física, libre desarrollo de la personalidad, igualdad y no discriminación. Estamos hablando de personas a quienes no se les reconoce como sujetos de derecho mientras no se sometan a esos requisitos (Díaz Díaz 2020). Por lo que es tarea de los jueces ordinarios realizar una interpretación del criterio a aplicar en los casos concretos a las luces del criterio interpretativo adoptado por la Corte Interamericana de Derechos Humanos en la reciente Opinión Consultiva OC-24/17.

A través de la Opinión Consultiva OC-24/17, la Corte ha señalado que la Convención Americana protege el derecho a la identidad, el cual se erige de la interpretación del derecho a la vida privada y al libre desarrollo de la personalidad (Díaz Díaz 2020). De esta manera la ha definido como, "el conjunto de atributos y características que permiten la individualización de la persona en sociedad y que, en tal sentido, comprende varios derechos según el sujeto de derechos de que se trate y las circunstancias del caso" (Opinión Consultiva OC-24/17, 2017, fj. 90). De igual manera, ha reconocido que de este derecho se desprende un derecho a la identidad de género el cual concibe como "la vivencia interna e individual del género tal como cada persona la siente, la cual podría corresponder o no con el sexo asignado al momento del nacimiento" (Opinión Consultiva OC-24/17, 2017, fj. 94).

Respecto al proceso de reconocimiento de la identidad de las personas trans, señala que los Estados deben considerar que

... el proceso de reconocimiento de la identidad de género no debe imponer a los solicitantes el cumplimiento de requisitos abusivos tales como la presentación de certificaciones médicas o pruebas de estado civil de no casados, tampoco se debe someter a los solicitantes al sometimiento a pericias médicas o psicológicas relacionadas con su identidad de género auto-percibida u otros que desvirtúen el principio según el cual la identidad de género no se prueba, por tanto el trámite debe estar basado en la mera expresión de voluntad del solicitante (Opinión Consultiva OC-24/17, 2017, fj. 129). 


\section{Asimismo, agrega que}

... los certificados médicos, psicológicos o psiquiátricos que se suelen requerir en este tipo de procedimientos, la Corte entiende que además de tener un carácter invasivo y poner en tela de juicio la adscripción identitaria llevada a cabo por la persona, descansan en el supuesto según el cual tener una identidad contraria al sexo que fue asignado al nacer constituye una patología (Opinión Consultiva OC-24/17, 2017, fj. 130).

Finalmente, también se pronuncia sobre los requisitos, señalando que,

(...) no podrá requerir que se lleven a cabo intervenciones quirúrgicas totales o parciales $\mathrm{ni}$ terapias hormonales, esterilizaciones $\mathrm{o}$ modificaciones corporales para sustentar el requerimiento, para otorgar lo solicitado o para probar la identidad de género que motiva dicho procedimiento, por cuanto podría ser contrario al derecho a la integridad personal contenido en el artículo 5.1 y 5.2 de la Convención Americana (Opinión Consultiva OC-24/17, 2017, fj. 146).

Como vemos, del caso peruano antes citado, la justicia ordinaria no viene resolviendo los procesos de cambio de sexo conforme a la Opinión Consultiva de la Corte Interamericana. Como es propio de un proceso judicial contencioso, se tendrán que valorar medios probatorios y desde ahí ya se rompe la premisa que postula la Corte que la identidad de género no se prueba. Un proceso judicial contencioso resulta incompatible con el principio de autodeterminación. Con el fallo constitucional del caso Ana Romero Saldarriaga se ha logrado el reconocimiento de un derecho a la identidad de género y se ha abierto la vía judicial ordinaria para su requerimiento, sin embargo, esta vía permite, en atención a la independencia judicial, que cada Juez aplique su criterio a cada caso concreto, exigiendo o valorando para su reconocimiento ciertos medios probatorios, que como hemos visto en el caso citado, generalmente son aquellos referidos a diagnósticos médicos sobre la identidad y sobre los cambios corporales practicados.

Esto es un riesgo que corre cada persona trans que desee hacer valer su derecho de acceso a la justicia para tener reconocida su identidad de género en su documento de identidad. Este es el problema que nos ha dejado el fallo constitucional del caso Ana Romero Saldarriaga al no haber sentado una doctrina clara sobre la autodeterminación del género, o por el contrario haber analizado y establecido con claridad los criterios a tener en cuenta por los jueces al resolver estas causas, sin excederse en exigencias abusivas o que 
afecten derechos fundamentales. Tenemos el reconocimiento constitucional de un derecho que en la práctica adolece de eficacia, porque cuando una persona trans acude al sistema judicial para su reconocimiento, no conoce cuál será el criterio a aplicar por el juez asignado, ni mucho menos cuál será el criterio del juzgado revisor en segunda instancia, a qué cambios debe someterse para iniciar el proceso judicial, qué medios probatorios serán valorados o exigidos, ni cuándo tendrá reconocido su derecho. Se embarca en un largo proceso dentro del cual tendrá que enfrentarse al mismo Estado representado por el RENIEC para poder tener reconocido un derecho fundamental, una lucha que debe continuar cada persona trans caso por caso.

En ese sentido, podemos entender que la problemática peruana actual radica ahora en la forma en la que se debe llevar a cabo el reconocimiento de la identidad de género, así como sus alcances. El modelo que propugna la Corte Interamericana de Derechos Humanos es aquel basado en la autodeterminación de la persona, que como ser libertad y por ende con dignidad, establece su proyecto de vida dentro del cual se encuentra su identidad. Esta problemática requiere de una respuesta oportuna en atención a que el modelo heteroasignado resulta lesivo en sí mismo, dado que obliga a la persona trans a someterse a procesos patologizantes sobre su identidad. Es necesario tener en cuenta que en 2019 la Organización Mundial de la Salud actualizó la Clasificación Internacional de Enfermedades (CIE 11), en la cual ya no considera a la transexualidad como un trastorno mental sino como una condición relativa a la salud sexual bajo el nombre de "discordancia de género" (Díaz Díaz 2020). En ese sentido, corresponde que la judicatura peruana deje de valorar la presencia de un diagnóstico para reconocer el derecho. La exigencia de estos requisitos perpetúa los estereotipos contra la población trans, teniéndolos como personas enfermas.

Como señalamos en un estudio anterior (Díaz Díaz 2020), es importante dejar atrás esa concepción patologizadora de las identidades trans, para considerarla como una cuestión jurídico-constitucional de derechos humanos, entendida como una manifestación del libre desarrollo de la personalidad, de la autodeterminación consciente y responsable a la que cada individuo tiene derecho (Salazar Benitez, 2019). Hasta la fecha, como señala Judith Butler (2016), "las vidas trans son negadas todo el tiempo, o transformadas en versiones patologizadas de lo que uno, una o unx desea" (p. 42). La violencia explícita que antes existía sobre este grupo minoritario desde tiempos remotos por parte del Estado subsiste hasta ahora, aunque disimulada y sustituida por la medicina, a la que el Estado le ha conferido el poder para situar una línea divisoria entre lo normal y lo patológico (García López, 2019, p. 162). Vemos como el Estado continúa ejerciendo la función de 
determinar la identidad de las personas, desde que nacen hasta en su etapa adulta, pese a que ya se ha reconocido un derecho a la identidad de género, se sigue adueñando de ese derecho para irrogarse la función de validar la identidad de las personas trans, nuevamente a través de los profesionales de la salud.

En la misma línea, el modelo heteroasignado también se caracteriza por la validación de los caracteres físicos de la persona trans, donde destacan los tratamientos o terapias hormonales. Estos si bien no comprenden una cirugía de reasignación sexual, puede conllevar a la esterilidad, al implicar cambios irreversibles en el cuerpo atentando contra el derecho a la integridad física, el que forma parte del derecho a la vida privada (Díaz Díaz 2020), como lo ha señalado el Tribunal Europeo de Derechos Humanos en el caso A.P. Garcon y Nicot vs. Francia, de 6 de abril de 2015 (apartado 94 y ss.), del mismo modo la Corte Interamericana en la OC-24/17. Cabe señalar, además que el tratamiento hormonal va contra los deseos de las personas trans que no desean alterar su cuerpo por su identidad. Recordemos que la identidad de género la lleva cada persona independientemente de su sexo biológico o su apariencia en tanto sus caracteres sexuales primarios y secundarios, por lo que la modificación corporal o genital va depender del deseo de cada persona.

Por otro lado, no todas las personas trans podrán acceder a la atención sanitaria para practicarse las modificaciones, teniendo en cuenta que en Perú este servicio no se encuentra cubierto por la Sanidad Pública. Aquí se presentarán otros problemas como son la autoasistencia o el recurrir a médicos clandestinos poniendo en riesgo su vida. Vemos que el proceso que actualmente se sigue en Perú para el reconocimiento de la identidad de género, pone a la persona trans en la situación de tener que decidir entre un derecho u otro, el derecho a su integridad física o el derecho al reconocimiento de su identidad de género.

La exigencia de estos requisitos se presenta como obstáculos lesivos a los derechos de las personas trans que deseen acceder al reconocimiento de su identidad, a los que se suma el largo proceso judicial, para lograr la rectificación de la mención registral del sexo en su documento de identidad, perpetuando que sigan sufriendo discriminación social. Asimismo, le impedirá el ejercicio de otros derechos de acuerdo a su condición sexual sentida y vivida, dado que se le niega su reconocimiento como tal, "un derecho sin el que obviamente el resto de los derechos carecen de sentido" (Salazar Benitez, 2019). Recordemos que la falta del reconocimiento de un derecho esencial como es la identidad, implica la negación de este grupo 
minoritario históricamente discriminado, perpetuando los estereotipos sobre ellos. Por lo que los profesionales de la salud deben actuar como acompañantes dejando de ostentar la facultad de determinar las formas de entender y vivir las identidades de las personas trans (Salazar Benitez, 2019), debiendo otorgarse soberanía a la voluntad humana sobre cualquier otra condición física, entendiendo que la libre autodeterminación del género ha de ser afirmada como un derecho humano fundamental (Ravetllat, 2017).

La atención oportuna del reconocimiento de su identidad, supone cambiarles la vida, de pasar de ser personas invisibles para el Estado a ser reconocidos como tales y que merecen protección (Díaz Díaz 2020). Mientras más exigencias se requieran para el reconocimiento de la identidad de las personas trans, más tarda la justicia en reconocerles este derecho y las consecuencias lesivas que eso produce pueden volverse irreparables. De esta manera, es necesario entender la importancia del oportuno reconocimiento de la identidad de las personas trans sin que se presenten obstáculos para ello. Recordemos que se trata de una población minoritaria históricamente discriminada, que para incluirse en la sociedad trata de invisibilizar su apariencia trans a través de cambios físicos que afectan su salud. Se ven obligados, muchas veces, a ir en contra de sus más profundos deseos de cómo llevar su propio cuerpo, sometiéndose a tratamientos médicos e incluso operaciones que deben solventar ellos mismos para encajar en las categorías binarias mujer/hombre y poder ser aceptados en una sociedad que rechaza lo diverso (Díaz Díaz 2020).

Esta falta de reconocimiento jurídico de su identidad ocasiona que vean dificultada su inclusión y el efectivo ejercicio de sus derechos como personas. La discriminación se presenta como barrera para que este grupo minoritario pueda ejercer en igualdad de oportunidades sus derechos. El acceso a la salud o al mercado formal de trabajo como principales derechos negados a este grupo que los reduce a condiciones precarias de vida, cuya supervivencia en su mayoría sobretodo de las mujeres trans se asienta en el ejercicio de la prostitución y con ello padecer un doble rechazo social en todos los ámbitos (Díaz Díaz 2020).

Cabe señalar que recientemente mediante sentencia de juzgado especializado en lo constitucional de Lima ${ }^{59}$, se ordenó al RENIEC la elaboración de un procedimiento administrativo para el reconocimiento de la identidad de género de las personas trans e intersex. El magistrado llega a señalar cuáles deben ser las exigencias máximas a requerir para poder realizar

59 Perú. Corte Superior de Justicia de Lima. Sentencia del Tercer Juzgado Constitucional Transitorio de Lima, en Proceso de amparo, de fecha 30 de julio de 2020. 
el trámite, el cual debe ser rápido y de preferencia gratuito, no debe exigir intervenciones quirúrgicas, tratamientos hormonales e incluso admitir una categoría adicional a masculino o femenino. De tal manera que sea exigible únicamente el consentimiento libre e informado del solicitante, en una clara muestra de atención a lo dispuesto por la Corte Interamericana de Derechos Humanos en su Opinión Consultiva OC-24/17. Cabe señalar que a través de esta sentencia se declara el estado de cosas inconstitucional, específicamente una "omisión inconstitucional", ante la inexistencia de un procedimiento que permita el cambio de nombres, sexo e imagen en el documento de identidad conforme a los parámetros señalados por la Corte Interamericana. Reconoce que, en virtud de ello, existe una vulneración sistemática al derecho a la identidad y al libre desarrollo de la personalidad (Díaz Díaz 2020).

Esta reciente sentencia es una muestra de que la justicia peruana está tomando conciencia sobre las necesidades de estas poblaciones minoritarias que durante años han venido sufriendo la discriminación y vulneración de sus derechos fundamentales en el Perú. Sin embargo, no se trata de una sentencia firme dado que ha sido apelada por el RENIEC, por lo que la causa será conocida por la Sala Superior de la Corte de Justicia de Lima. Pese a ello es importante reconocer que se trata de un avance importante en materia de derechos fundamentales de grupos minoritarios históricamente desplazados, que ahora queda en manos de la Sala Superior la decisión (Díaz Díaz 2020).

Interesante punto es el que aborda esta última sentencia, en tanto que, dentro de sus propuestas incluye agregar una categoría adicional a mujer $u$ hombre dentro de las posibilidades de género a transitar por las personas trans. Este punto no ha sido tocado por la OC 24-17, no obstante, se encuentra estrechamente vinculado con el modelo basado en la autodeterminación, el reconocer las identidades más allá del modelo binario de sexo/género mujer/hombre, entendiendo que todas las personas son diversas en sí mismas y que requieren protección jurídica. Adicionalmente podemos hablar de otro punto que no ha sido tocado en la OC 24-17 y tampoco por la reciente sentencia peruana, es el caso de la fluidez del género y que ya varios países de la región ${ }^{60}$ lo contemplan en sus legislaciones sobre reconocimiento de la identidad de género. Aquel referido a que una vez realizado el cambio de la mención del sexo en el documento de identidad, éste pueda variarse posteriormente, ya sea volviendo al sexo de origen o transitar hacia otro, en caso se haya admitido un tercer género.

60 Ley Argentina de Identidad de Género nro. 26.743, aprobada en 2012; Decreto 1227 de Colombia, aprobado en 2015; Ley Chilena nro. 21120, aprobada en 2018; Ley Boliviana nro. 807, aprobada en 2016 
Sobre estos puntos podemos citar el caso de Bélgica y su modelo no binario, electivo y además fluido. Cuyo reciente pronunciamiento de su Corte Constitucional $^{61}$ sobre la ley de 25 de junio de 2017, constituye un aporte interesante sobre el no binarismo y la fluidez del género. En esta sentencia se reconoce que el derecho a la identidad de género está amparado por el derecho a la vida privada y familiar, además una vez que se acepta que el principio de autodeterminación debe ser el principio rector en la materia, no se puede dejar de reconocer la existencia de identidades no binarias (Rubio y Osella 2020, p. 68). Es decir, el reconocimiento de identidades no binarias encuentra sustento en la autodeterminación. Y que independientemente de que exista un reconocimiento constitucional a las categorías de mujer y hombre para sancionar la igualdad de derechos de éstos, no significa que son un reflejo del binarismo como rasgo basilar del ordenamiento constitucional que impidan adoptar medidas para luchar contra la discriminación basada en la identidad de género no binaria (Rubio y Osella 2020, p. 68).

Del mismo modo, reconoce que la identidad de una persona puede evolucionar en el tiempo y nos corresponderse a su fuero interno, por lo que resultaría discriminatorio a las personas con identidad de género fluida impedir posteriores cambios, máxime si no produce una afectación de personas con identidades binarias o no fluidas (Rubio y Osella 2020, p. 69). Podríamos incluir en este modelo constitucional a las legislaciones de Uruguay y Argentina. Dado que Uruguay con su Ley de personas trans reconoce a las personas trans como aquellas, que incluso se identifican fuera de las categorías binarias ${ }^{62}$. Así como el caso de Argentina donde a través de un reciente fallo judicial en la región de Tierra del Fuego en diciembre de 2019 (Infobae.com, 2019), se admitió un recurso de amparo ordenando al Registro Civil la inscripción de una persona bajo la nominación del sexo "no binario/ igualitario" y se expida una nueva partida de nacimiento y documento de identidad con dicha descripción. Esta persona recurrió a la vía judicial dado que no se percibía ni como hombre ni como mujer y había sido denegado su pedido por el Registro Civil, lo que fue amparado por la justicia en atención al principio de autodeterminación.

\section{CONCLUSIONES}

- Retomando la doctrina del profesor Fernández Sessarego, para un correcto abordaje del tema es necesario entender la estrecha relación

Cour Constitutionelle, Arret n 99/2019 du 19 juin 2019, numéro de role 6813. En: https:/ /bit.ly/2vJVtf2

Ley 19684, de 26 de octubre de 2018, señala en su artículo 4 inciso c) que "Persona trans: la persona que se autopercibe o expresa un género distinto al sexo que le fuera asignado al momento del nacimiento, o bien un género no encuadrado en la clasificación binaria masculino femenino, independientemente de su edad y de acuerdo a su desarrollo evolutivo psicosexual." (negrilla agregada) 
entre la identidad, libertad y dignidad humana, dado que sobre ellos descansa el sustento de la autodeterminación de las personas. Como lo confirmara años después la Corte Interamericana de Derechos Humanos, "un aspecto central del reconocimiento de la dignidad de las personas es la posibilidad de todo ser humano de autodeterminarse" (Opinión Consultiva OC-24/17, 2017, fj. 88). Al reconocer ello, partimos de la concepción que la persona es quien construye su propia identidad y que no hay nadie mejor que él mismo para determinarla.

- Es momento de sentar las bases de que todas las personas son diversas y únicas en sí mismas, esto nos lleva a pensar que es imposible concebir que todas encajarán en sólo dos tipos de cuerpo, identidad de género, orientación sexual, entre otros aspectos. Entonces, así como la persona humana es diversa en atención a su libertad como seres con dignidad, el derecho no puede limitarse en tutelar dos únicos tipos de cuerpos y un sistema en general basado en la heteronormatividad. De lo contrario únicamente se estaría brindando protección jurídica a determinadas personas con ciertas características bajo la consideración de que son "normales" y patologizando a quienes se apartan de la norma, lo que ha venido haciendo la medicina en especial la psiquiatría a lo largo de la historia con la población trans. Esto ha implicado otorgar un poder a ciertas instituciones, como la Asociación Americana de Psiquiatría (APA) o la Organización Mundial de la Salud (OMS), para que clasifiquen aquello considerado fuera de la norma como una enfermedad que necesita tratamiento, encubriendo en la realidad una forma de castigo y exclusión, que la sociedad ha interiorizado como lo verdadero, generando el rechazo o la aversión que se traduce en la discriminación y violencia contra este grupo.

- ¿Estamos hablando entonces que el derecho solo debe proteger a ciertos tipos de personas de acuerdo a su corporalidad o preferencia sexual o identidad personal? Debemos recordar que los derechos humanos tienen su sustento en la dignidad de la persona humana, reconociendo la dignidad indesligable de la naturaleza humana y que independientemente de sus propias características, sin distinción, toda persona es titular de derechos y debe poder ejercerlos en igualdad de condiciones. En ese sentido, es tarea de los Estados tutelar que ese ejercicio de los derechos se realice en igualdad de condiciones por todos y eliminar la concepción patologizadora de las identidades diversas que son una clara muestra de la 
diversidad propia de los seres humanos, de nuestra esencia y no una anormalidad, una tarea que sigue quedando pendiente en Perú.

- El presente estudio nos lleva a entender cómo la doctrina de la identidad personal impulsada por el profesor Fernández Sessarego en 1988 ha servido de influencia para el desarrollo del derecho peruano en la materia. La identidad personal que encuentra sustento en la libertad y dignidad humana, el reconocer que la persona define su identidad a lo largo de su vida, moldeándose constantemente de acuerdo a sus más profundas aspiraciones conforme va construyendo su proyecto de vida con libertad. De esta manera no es posible concebir la identidad únicamente desde el plano estático, sino que importa también un extremo dinámico y es donde se ubica la identidad de género.

- La influencia de este desarrollo doctrinal lo hemos visto reflejado en los fallos del Tribunal Constitucional, por el cual se entendió al derecho a la identidad consagrado en la Constitución, más allá de una mera identificación. En 2006, reconoció la clasificación doctrinal de la identidad y la adopta como aquella conformada por elementos objetivos y subjetivos (estáticos y dinámicos). Pero también existieron retrocesos en el reconocimiento de este derecho, con la sentencia del caso Pamela Estela Mendoza Moreno en 2014, donde se consideró a la transexualidad como una patología y que el sexo como un elemento estático, inmutable y por ende indisponible de la identidad, cerrando la posibilidad de demandar su rectificación. No pasarían muchos años para que este precedente sea dejado sin efecto, hasta 2016 con la última sentencia del TC en el caso Ana Romero Saldarriaga, por el cual se despatologiza la transexualidad y se considera al sexo como un elemento dinámico de la identidad, como una construcción que no se reduce a la mera biología sino que se forma también dentro de las realidades sociales, culturales, interpersonales que la propia persona experimenta durante su vida, reconociendo la existencia de un derecho a la identidad de género como parte del contenido constitucionalmente protegido del derecho a la identidad personal, consagrado en la Constitución peruana.

- De esta manera, se ha dado pase al surgimiento de nuevos problemas, como es la forma de reconocimiento que debe darse a este derecho para que las personas trans puedan ejercerlo y sus alcances. Es aquí donde analizamos los vacíos que ha dejado este 
fallo constitucional de 2016, en tanto que no se define con claridad si apunta a un modelo constitucional basado en la autodeterminación o la heteroasignación, si las personas trans solamente pueden transitar dentro de las categorías binarias de género o si se permite la fluidez del género. Algunas respuestas las podemos encontrar en la jurisprudencia internacional de los derechos humanos por parte de la Corte IDH, que en su último pronunciamiento en la materia en la Opinión consultiva OC-24/17 ha reconocido la existencia de un derecho a la identidad protegido por la Convención Americana que se sustenta en el libre desarrollo de la personalidad y la vida privada, en estrecha relación con la autonomía de la persona. Asimismo, ha dispuesto que los Estados deben implementar un proceso basado en el consentimiento libre e informado del solicitante, sin la exigencia de requisitos invasivos y abusivos como certificaciones médicas o psicológicas, o de operaciones quirúrgicas o tratamientos hormonales que son contrarios a la integridad personal. La naturaleza del proceso de reconocimiento debe ser administrativo o notarial libre de escrutinio y validación externa de la identificación sexual y de género de la persona que lo solicita (Agurto Gonzales y Díaz Díaz 2020). De otro lado que reafirma la aplicación de los derechos contenidos en la Convención Americana a los menores de edad atendiendo a su autonomía progresiva.

- Sobre estos vacíos en el fallo constitucional también encontramos respuestas en la doctrina del profesor Fernández Sessarego que toma vigencia ante estos nuevos retos del derecho a la identidad de las personas trans. Recordemos que el derecho a la identidad se sustenta en la libertad de la persona humana, en esa libertad de ser uno mismo y no otro en atención a que cada persona elabora su propio proyecto de vida, como seres con dignidad. El proyecto de vida del cual forma parte la construcción de la identidad de la persona, se encuentra en continuo movimiento y contiene elementos dinámicos. El sexo al ser un elemento dinámico de la identidad, como también ha sido considerado por el Tribunal Constitucional peruano, no es posible reducirlo a la inmutabilidad una vez realizada la transición, bajo ese entendimiento podría justificarse posteriores cambios reconociendo la fluidez del género. Asimismo, tampoco es posible tutelar únicamente la identidad dentro de las categorías de género dicotómicas mujer-hombre, considerándose el no binarismo.

- El aporte de la jurisprudencia internacional de los derechos humanos resulta de vital importancia aunado con la doctrina 
peruana para completar esos vacíos interpretativos dejados por el último fallo constitucional peruano. El mecanismo de inclusión del fallo internacional se puede alcanzar a través del control de convencionalidad, aunque esto solo recae en la autonomía de los jueces en cada caso concreto. Dado el caso analizado del reconocimiento de la identidad de una persona trans en la provincia de Arequipa Perú, es una muestra de cómo la judicatura peruana está operando sin la aplicación de los estándares internacionales de derechos humanos. La OC-24/17 aún no se materializa en el Perú, ni en la forma de resolver de los magistrados, ni tampoco en la aprobación de una ley de identidad de género que cierre por fin los vacíos y la incertidumbre en torno a la forma del reconocimiento y sus alcances, una tarea que todavía se encuentra pendiente.

\section{REFERENCIAS}

A.A.V.G, 05684-2016 (Segundo Juzgado Civil del Módulo Básico de Justicia de Paucarpata, Arequipa 5 de enero de 2018).

Agurto Gonzales, C., \& Díaz Díaz, M. (2020). El derecho a la identidad personal frente a la problemática del COVID-19. Recuperado de https:/ / www.comparativecovidlaw.it/2020/06/15/el-derecho-a-laidentidad-personal-frente-a-la-problematica-del-covid-19/

Butler, J. (2016). Transexualidad, transformaciones. En G. Coll Planas et al., El género desordenado, críticas en torno a la patologización de la transexualidad. Madrid: Egales.

Díaz Díaz, M. (2020). La problemática jurídica del reconocimiento de la identidad de género y su impacto en las mujeres trans. Estudio comparado de la realidad socio jurídica española y peruana (Trabajo de Fin de Máster inédito). Universidad de Salamanca, Salamanca, España.

Fernández Sessarego, C. (2006). La Constitución comentada (Vol. II). Lima: Gaceta Jurídica.

Fernández Sessarego, C. (2010). La problemática del transexualismo. En C. Fernández Sessarego et al., Los registros y las personas, dimensiones jurídicas contemporáneas (págs. 732-783). Lima: Registro Nacional de Identificacción y Estado Civil. 
Fernández Sessarego, C. (2015). El derecho a la identidad personal. Lima: Instituto Pacífico.

García López, D. (2019). La marca del derecho: violencias sistémicas sobre las personas trans. En S. López Rodríguez et al., Cuerpos marcados, vidas que cuentan y políticas públicas. Barcelona: Bellaterra.

Infobae.com. (18 de Diciembre de 2019). Tierra del Fuego: autorizaron a una persona a inscribirse con género "no binario" en el DNI. Obtenido de Infobae.com: https://www.infobae.com/sociedad/2019/12/18/ tierra-del-fuego-autorizaron-a-una-persona-a-inscribirse-congenero-no-binario-en-el-dni /

Opinión Consultiva OC-24/17 (Corte Interamericana de Derechos Humanos 24 de noviembre de 2017).

Ravetllat, I. (2017). El derecho a la identidad (de género) de la infancia y la adolescencia: del paradigma de la patología a la autodeterminación. Actualidad Civil, 42-62.

Rubio, R., \& Osella, S. (2020). El nuevo derecho constitucional a la identidad de género: entre la libertad de elección, el incremento de categorías y la subjetividad y fluidez de sus contenidos. Un análisis desde el derecho comparado. Revista Española de Derecho Constitucional, 45-75.

Salazar Benitez, O. (2019). El derecho a la identidad sexual de las personas menores de edad. Comentario a la STC 99/2019. Revista de Derecho Constitucional Europeo. Recuperado de https://www.ugr.es/ redce/ REDCE32/articulos/09_SALAZAR.htm

Tribunal Constitucional, Expediente 2273-2005-PA/TC (21 de octubre de 2006).

Tribunal Constitucional, Expediente 139-2013-PA/TC (18 de marzo de 2014).

Tribunal Constitucional, Expediente 6040-2015-PA/TC (21 de octubre de 2016).

Villaverde, I. et al.(2004). Teoría general de los derechos fundamentales en la Constitución española de 1978. Madrid: Tecnos. 
Zamudio, M. L. (2010). La identidad como derecho fundamental. En M. Zamudio et al., Los registros y las personas, dimensiones jurídicas contemporáneas (pág. 158). Lima: Registro Nacional de Identificación y Estado Civil.

Fecha de recepción: 11-09-2020

Fecha de aceptación: 09-11-2020 